\title{
2015 Proceedings
}

\section{Chinese Garden from Upcycled Used Clothing}

Ling Zhang and Chanmi Hwang

Iowa State University, USA

Keywords: Upcycling, Used Clothing, Chinese Garden, Laser Cutting

With fast changing fashion trends, textile-based waste has become a significant environmental problem (Claudio, 2007). In United States, an average of 68 pounds of clothing were thrown

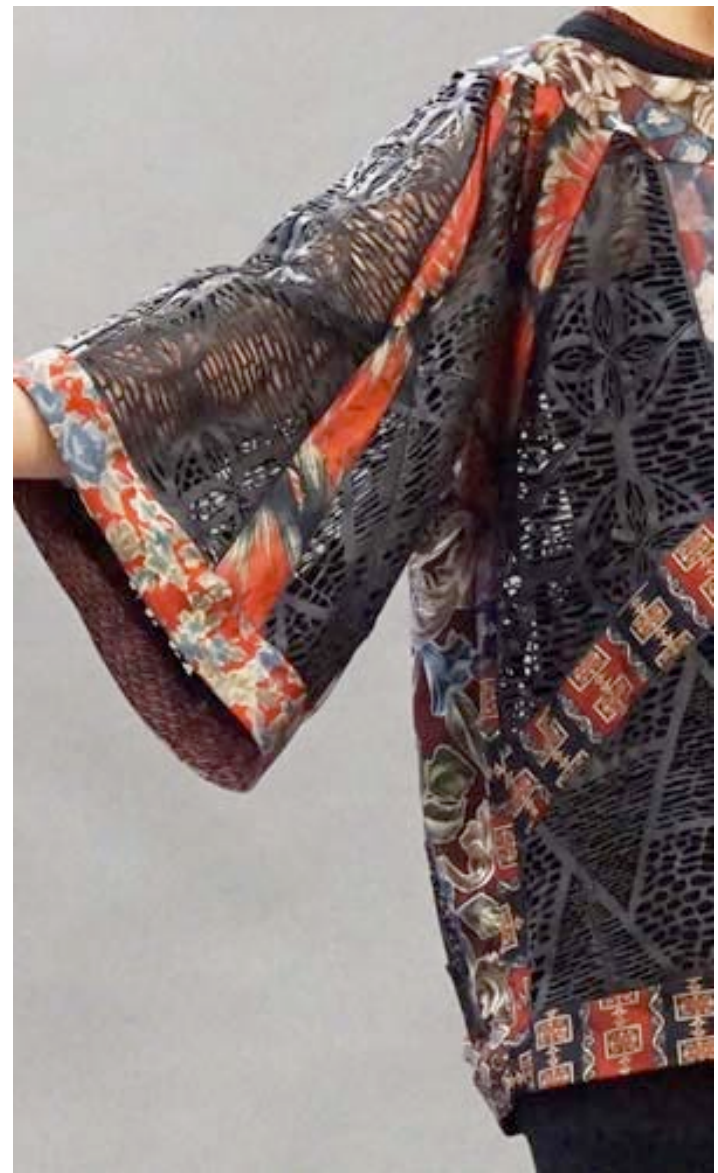

Figure 1. Detail of laser cutting pattern away per person per year (Claudio, 2007). Landfill is usually the ultimate destination of the used clothing, thus huge quantities of valuable materials and components are lost. Creating upcycled garments inspired by the aesthetics of a Chinese garden and the philosophies of Taoism was the main purpose of this project, plus the yin-yang aesthetic principles which emphasized the blend of hard and soft, simple and magnificent. Unlike recycling, upcycling converts waste materials innovatively into new products with a value-added quality instead of just reusing the materials (Aus, 2011).

The silhouette of the jacket was inspired by traditional Chinese clothing in the Tang dynasty characterized by wide borders on the neckline and sleeves cut-in-one with the body of the garment. Flat pattern techniques were used to create the dart-less jacket pattern. Two second-hand women's leather jackets were disassembled along the constructional seam lines (e.g. arm holes, side seams) and materials (leather, lining). Only the fashion fabrics from eighteen deconstructed men's neckties were used to create borders between laser cutting pieces, which represent the doors and windows in Chinese garden. The laser cut motifs were digitally drawn in Adobe Illustrator by pen tool with different width lines based on a photo taken of the elaborate hand-laid patterns in the courtyard floors located at the center of the Humble Administrator's Garden in Suzhou, China. The thirteen paper patterns of the jacket for laser cutting were digitized into Opti-Tex and arranged based on the shape and size of the deconstructed leather pieces. The 
contrast between the leather and neckties, and solid black with busy prints ideally depict the Taoism (yin-yang) aesthetic principles.

This project demonstrates three unique advantages. Compare to common ways of upcycling neckties which are limited by the shape, we introduce flexibility into upcycling focusing on transforming the textures, colors, and prints of neckties into new design elements: these new design elements are not recognized as neckties anymore. Secondly, the laser cutting technology can restructure the surface of the second-hand leather, remove wear-and-tear, and rejuvenate this type of fabric. Lastly, it is also a sustainable design process of using second-hand textile materials that alleviate the impacts of environmental problems.

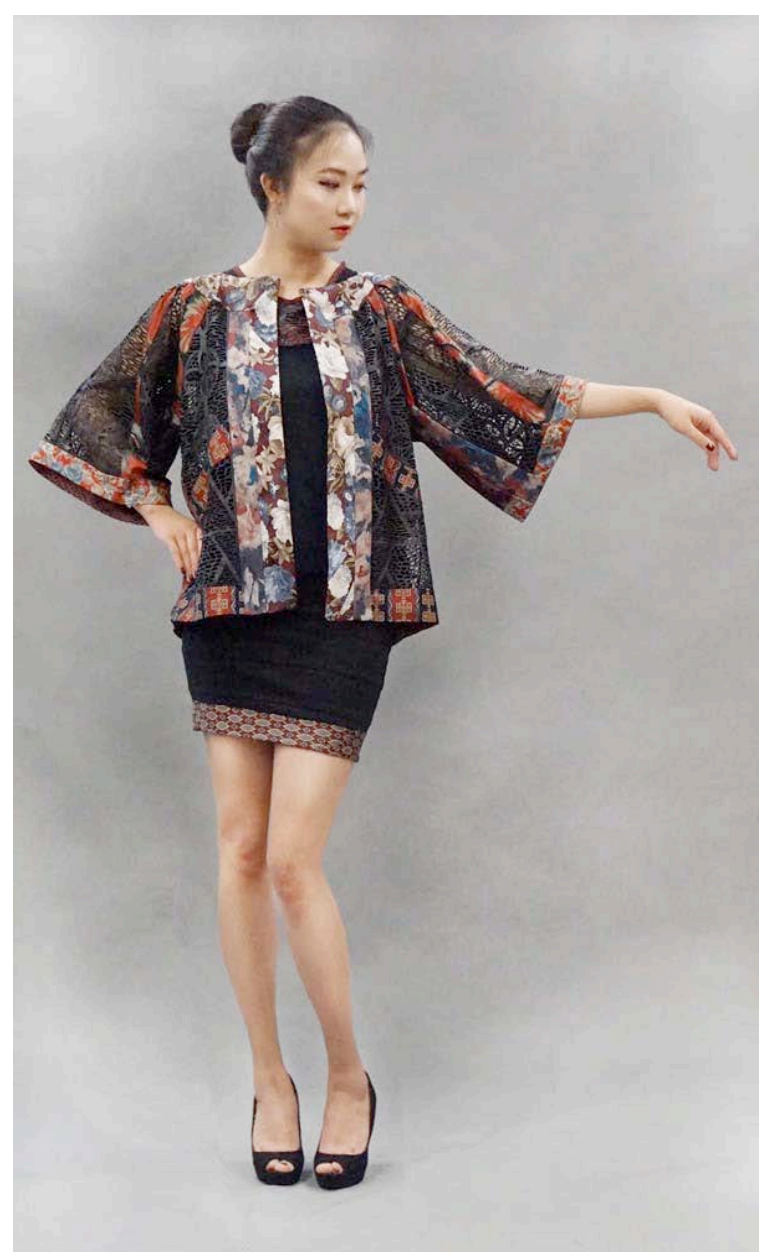

Figure 2. Front view

\section{References:}

Aus, R. (2011). Trash to trend-Using upcycling in fashion design. Unpublished doctoral dissertation, Estonian Academy of Arts, Tallinn, Estonia.

Claudio, L. (2007). Waste couture: environmental impact of the clothing industry. Environmental Health Perspectives, 115 (9), 449-454. 